\title{
Editorial: Looking through the Johari window
}

\author{
Sandy Oliver* - UCL Institute of Education, UK
}

Sophie Duncan* - National Co-ordinating Centre for Public Engagement, UK

Research for All is dedicated to research that involves universities and communities, services or industries working together. The aim of these different groups working together is not only to share existing knowledge held by each of them, but also to build on existing knowledge in ways that groups of similar people struggle to do alone. Our own knowledge is always partial, with gaps and preferences that may differ from the gaps experienced and preferences held by other people. Bringing together people with different perspectives not only allows learning from each other, but also allows learning that is new to everyone involved.

A first step is recognizing that each of us has our own way of looking at issues, and we may each be missing out if we do not enquire about how other people see them. Thinking about our different perspectives, blind spots and potential for learning together can be prompted by the visual model of the Johari window (Luft, 1961), named after its creators, Joseph Luft and Harrington Ingram.

The Johari window was originally designed to encourage self-awareness and communication about behaviour. Rather than use it to investigate knowledge about ourselves as individuals, we have adapted it to analyse knowledge (and assumptions) about our world accrued from the perspectives open to different groups of people (see Figure 1). Instead of considering what is 'known to self' and 'known to others', which makes the Johari window helpful in psychology, we can consider what is 'known to us' and 'known to others' when thinking about research as a collective activity. Another change to the original model is recognizing that what is seen from multiple standpoints may be different yet equally important. Thus, analysing these differences may start with 'us the researchers' or 'us the community' or 'us the service providers' or 'us the policymakers' or 'us the practising artists' or 'us the volunteers', and so on, depending on the situation.

Figure 1: Familiar and unfamiliar knowledge

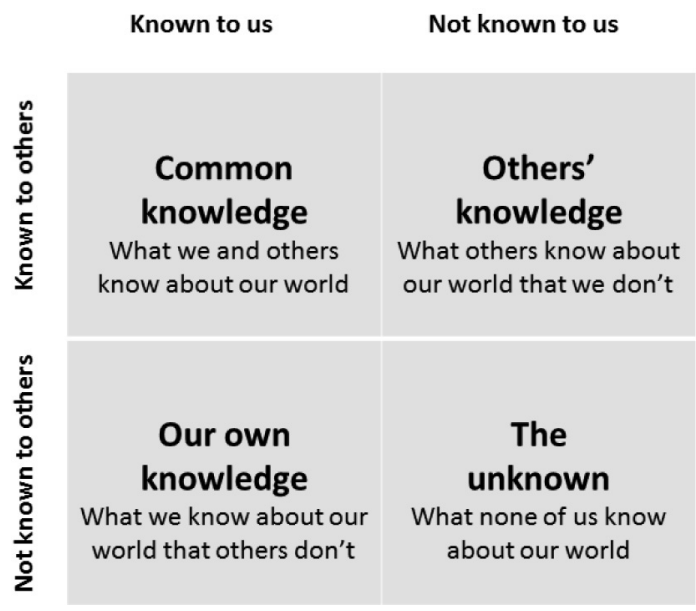

* Corresponding authors - emails: sandy.oliver@ucl.ac.uk; sophie.duncan@uwe.ac.uk @Copyright 2019 Oliver and Duncan 
The value of public engagement with research becomes apparent when recognizing that only some knowledge is widely held (common knowledge); that although we may hold some specific knowledge not held by others, they also hold specific knowledge not held by us; and that some aspects of the world around us are unknown to all of us.

In the public understanding of science tradition, 'us researchers' seek to increase 'common knowledge' by translating research-based knowledge from its technical or professional language - or jargon - into plain language for wider understanding (see Figure 2). Greater common knowledge has also been pursued in the public consultation tradition, by researchers seeking experiences and ideas from outside academia to inform their own work (see Figure 3). In each case, researchers either seek to teach the public or to learn from the public.

Figure 2: Sharing our knowledge with others

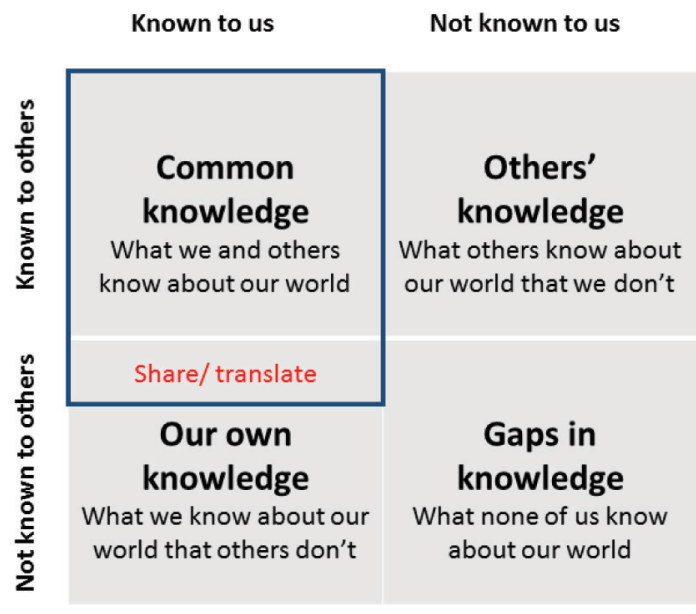

Figure 3: Seeking knowledge from others

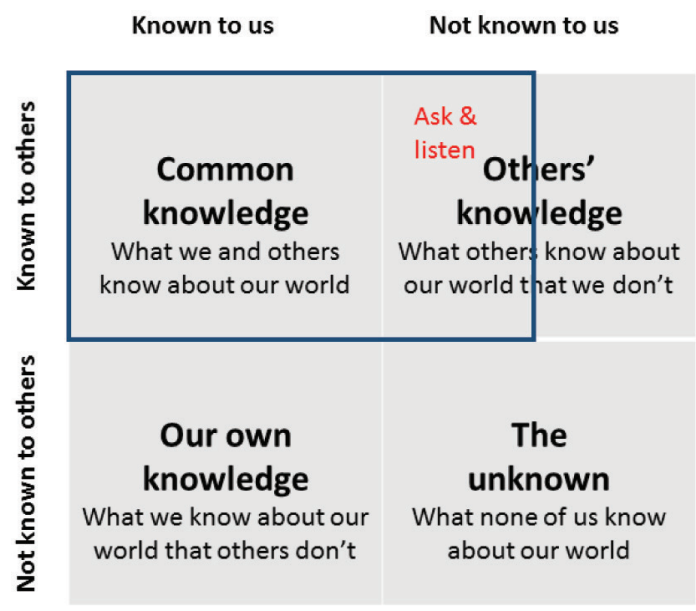

Clearly, the Johari window can be applied to different groups. In the case of engaged research, rather than starting with 'us researchers', we can, instead, start with 'us the public'. In this sense, the initial focus is on the public sharing their knowledge, and researchers become the 'others'. This happens when activists increase common knowledge by lobbying researchers with their concerns, for instance about pollution 
or side effects of drugs. Similar to researchers, rather than only sharing their own knowledge, community groups may also seek out others' learning, such as by drawing on research to inform their work.

Researchers and community organizations working in partnership offers more than exploring their own and others' knowledges. It opens up the opportunity for new learning that neither group knew before. In this way, new knowledge is co-produced (see Figure 4).

Figure 4: Generating new knowledge with others

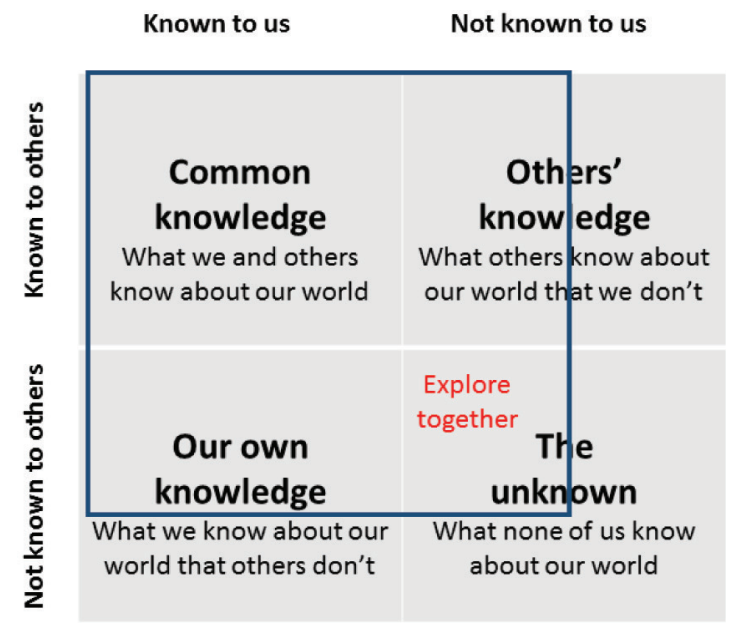

Figure 5: What patients and researchers know about Lyme Disease

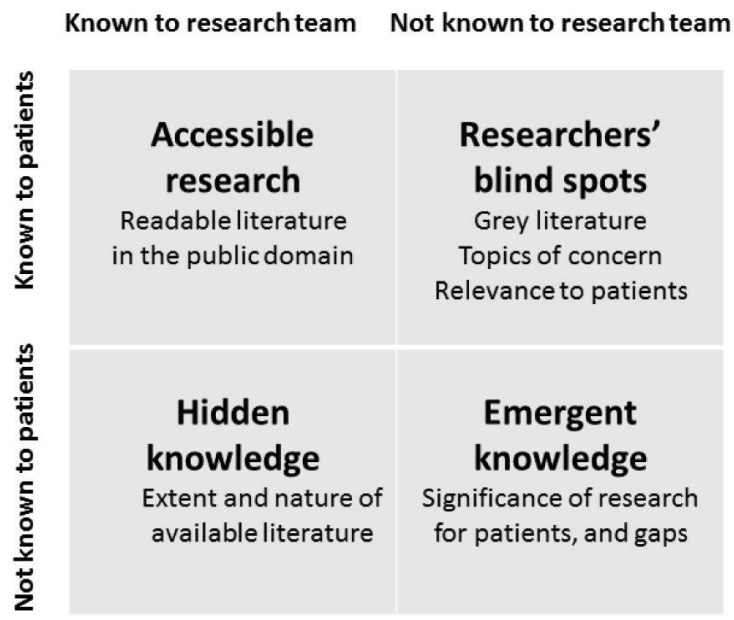

What this means in practical terms becomes apparent when a research team involved patients in discussions about the research available about Lyme Disease (Stokes and Sutcliffe, 2018), as illustrated in Figure 5. Only some research was readily available to anyone interested; much was hidden to all except researchers with the skills and library resources to find it. At the same time, the research team knew less about research only available through Lyme Disease networks, and even less about patients' concerns and the relevance of the research to patients. Only by working together could researchers and patients assess the significance of the total knowledge available, and the important gaps in that knowledge. 
This recognition of the synergies arising from researchers working with patients and clinicians underpins many efforts to set research priorities in health collaboratively (Crowe et al., 2015) and to set national standards for public involvement in research (NIHR, 2018). The Johari window also clarifies how blind spots arise from specific research methods, and how to overcome them by being open to a range of research methods (Oliver et al., 2018).

It is overcoming blind spots, revealing hidden knowledge and discovering real unknowns that implicitly or explicitly motivate the authors of Research for All articles. Some authors make great efforts to share the knowledge they hold that is hidden to other people - the basis of public understanding of science. Exemplifying this approach is a glossary explaining evaluation terms in plain language, helping general readers understand texts about evaluating health treatments (Moberg et al., 2018). This glossary was developed largely by taking knowledge from the world of research and translating it for a wider readership. However, offering explanations from the world of research was insufficient, so the glossary authors also invited feedback from potential users - translating what they knew effectively was only successful when they also drew on other people's experience.

This issue of Research for All contains four more articles featuring science communication. Although these projects were led by researchers, all the authors also drew on others' experience. A campaign to raise awareness of research, \#WhyWeDoResearch, became 'a community where patients, staff and public alike can share their voices about health research on an equal playing field', with tweetchats hosted by either researchers or patients, each bringing their own expertise (Yhnell et al.). An interactive immersive street game for navigating science and politics in flood management not only made complex scientific issues more relatable to the players, but its collaborative development process also allowed scientists to become creative communicators (Wendler and Shuttleworth). Developers of digital games for communicating research discovered how involving university students collaboratively allowed the creation of games that reflected the students' own interpretations of research (lacovides et al.). A fourth project in this issue aiming to communicate science - in this case seeking to communicate a love of science - was at the heart of a widening participation programme. Again, although the aim was to enhance public understanding of science by encouraging wider participation in higher education, the co-production approach encouraged a critical student voice that was essential to improving the course (Campbell et al.).

A set of three articles emphasizes the value of collective reflection to generate new knowledge. A letter-writing scheme that encouraged older people and university students to reflect on historical archive material enhanced understanding about 'the relationship between loneliness, home and belonging in students, as well as in long-standing, older members of the community' (Binnie). Harvey et al. reflect on the use of theatre to explore 'otherness' and demonstrate that 'theatrical performance can function as a public pedagogy of solidarity by giving the audience an affective, embodied experience through which they relate their own experience to that of the characters on stage'. Brown and Ward reflect and challenge each other on their direct experiences of a collaborative project to reveal the implications of discrimination and power in university relationships with wider communities.

Dunleavy et al. focus not on changing the size of particular panes in the Johari window, but on helping to open any of the window panes wider, with 'publicly engaged research managers', emphasizing the soft skills that are crucial for supporting collaboration and co-production. 
Using the Johari window to examine Research for All articles highlights both commonalities and gaps. All of the articles address increasing common knowledge by drawing on knowledge held by both researchers and others. This may be the feature that distinguishes them from enhancing common knowledge by didactic teaching or by qualitative research alone.

This distinction of 'us' and 'others' in the Johari window may aid our understandings, but the terms can feel problematic. We also know that the world is more complicated. People wear many different hats, have blended or hybrid roles, and may move in and out of higher education. Our professional and personal lives may see us looking through different panes of the Johari window simultaneously. Researchers who hold two roles provide unique perspectives on how knowledge can be co-created, shared and understood. Research for All is keen to include more articles from these people. Changing 'us' researchers to 'us' in the wider world highlights another gap in our articles. Research for All is also keen to include more contributions from organizations that use research to inform their own work. Thinking of 'us' the UK editors, we would also like to attract more contributions from 'others' in the wider world, especially the global South.

The Johari window illustrates neatly the various purposes of research engagement and helps portray the added value of engagement across the field, not just individual projects. Applying it to Research for All reveals important gaps among our contributing authors. It also confirms the Johari window as a useful analogy that may help analyse research engagement further by considering not just the angle seen through each pane, but also how clearly we can see through each pane, the value given to the views offered by different panes, and the ease, willingness and help available for opening each pane.

\section{Articles in this issue}

Binnie, G. (2019) 'Loneliness and the letter: Co-developing cross-generational letter writing with higher education students and older people'. Research for All, 3 (1), 59-73.

Brown, M. and Ward, P. (2019) 'Communities, universities and ethnicity: A conversation from Imagine: Connecting Communities Through Research'. Research for All, 3 (1), 91-104.

Campbell, S., Gazard, B., Woodhead, C., Harber-Aschan, L., Beards, S., Harber-Aschan, J., Gazzard, M., Yaman, E., Murugesu, A. and Hatch, S.L. (2019) 'Involving young people through co-production and widening participation approaches: Reflections from a school-based engagement initiative'. Research for All, 3 (1), 42-58.

Dunleavy, K., Noble, M. and Andrews, H. (2019) 'The emergence of the publicly engaged research manager'. Research for All, 3 (1), 105-24.

Harvey, L., McCormick, B., Vanden, K., Collins, R. and Suarez, P. (2019) 'Theatrical performance as a public pedagogy of solidarity for intercultural learning'. Research for All, 3 (1), 74-90.

lacovides, I., Cox, A., Furniss, D., Stawarz, K., Jennett, C. and Adams, A. (2019) 'Supporting engagement in research through a game design competition'. Research for All, 3 (1), 25-41.

Wendler, J. and Shuttleworth, E.L. (2019) 'Downpour! - Flood risk communication through interactive immersive street games'. Research for All, 3 (1), 18-24.

Yhnell, E., Smith, H.A., Walker, K. and Whitehouse, C.L. (2019) '\#WhyWeDoResearch: Raising research awareness and opportunities for patients, public and staff through Twitter'. Research for All, 3 (1), 7-17.

\section{Acknowledgements}

Research for All is a collaborative project that relies on a range of associate editors with experience of engaged research in a variety of contexts. The associate editors who advised us on the content for this issue of the journal are: 
- Mark Charlton - De Montfort University, UK

- Jamie Gallagher - University of Glasgow, UK

- Ceri Davies - University of Brighton, UK

- Ann-Marie Houghton - University of Lancaster, UK

- Janet Jull - Bruyère Research Institute and University of Ottawa, Canada

- Natalia Kucirkova - UCL Institute of Education, UK

- Sarah Lloyd - University of Hertfordshire, UK

- Kate Pahl - Manchester Metropolitan University, UK

- Allison Tong - University of Sydney, Australia

- Crystal Tremblay - University of Victoria, Canada

- Claire Wood - University of Leicester, UK

We extend our thanks to them and to all the expert reviewers - two for each contribution - who helped us guide authors towards their final drafts.

\section{References}

Crowe, S., Fenton, M., Hall, M., Cowan, K. and Chalmers, I. (2015) 'Patients', clinicians' and the research communities' priorities for treatment research: There is an important mismatch'. Research Involvement and Engagement, 1, Article 2, 1-10. Online. https://tinyurl.com/y7oqwpav (accessed 13 November 2018).

Luft, J. (1961) 'The Johari Window: A graphic model of awareness in interpersonal relations'. Human Relations Training News, 5 (1), 6-7.

Moberg, J., Austvoll-Dahlgren, A., Treweek, S., Badenoch, D., Layfield, R., Harbour, R., Rosenbaum, S., Oxman, A.D., Atkinson, P. and Chalmers, I. (2018) 'The plain language Glossary of Evaluation Terms for Informed Treatment choices (GET-IT) at www.getitglossary.org'. Research for All, 2 (1), 106-21.

NIHR (National Institute for Health Research) (2018) National Standards for Public Involvement in Research. London: National Institute for Health Research. Online. https://tinyurl.com/y7mnstuc (accessed 13 November 2018).

Oliver, S., Graziosi, S., Roche, C., Hill, S. and Welch, V. (2018) 'Blind-spot analysis and evidencebased initiatives: Shining a light on methodological innovations'. Paper presented at the Global Evidence and Implementation Summit (GEIS), Melbourne, 22-24 October 2018.

Stokes, G. and Sutcliffe, K. (2018) 'Maps are for everyone: PPI in systematic evidence maps can have significant benefits for understanding findings, relevance and application'. Paper presented at the Cochrane Colloquium, Edinburgh, 16-18 September 2018. 